\title{
Residential self-selection, built environment, and travel behavior in the Chinese context
}

\author{
Donggen Wang ${ }^{1}$ \\ Hong Kong Baptist University
}

\author{
Tao Lin \\ Hong Kong Baptist University
}

\begin{abstract}
Residential self-selection has been reported to be a factor confounding the observed relationship between built environment and travel behavior. By incorporating residential self-selection, studies have generated much insight into the causalities involved in the relationship between built environment and travel behavior. However, most of these studies were conducted in North American cities, where individuals may have the opportunity to realize their preferences in residential and transport mode choices. There are not many similar studies for other parts of the world, such as China, where residential and transport choices are probably more constrained than in North America. This paper aims to partly fill the gap by discussing the specificities of the residential self-selection issue in urban China and suggesting how to cope with this issue when examining the relationship between built environment and travel behavior in the Chinese context. We argue that studies addressing the residential self-selection issue in China need to consider the housing source, which has implications for residential choice, and acknowledge the importance of some travel-related attitudes such as preferences for short commutes, good accessibility to public transport, and proximity to markets for daily goods shopping.
\end{abstract}

Keywords: Residential self-selection, built environment, travel behavior, travel attitude, urban China

\section{$1 \quad$ Introduction}

The proposition that the observed association between built environment and travel behavior may be at least partly attributable to residents' travel-related attitudes has aroused much research interest about residential self-selection, which denotes the propensity of people choosing residential location based on travel attitudes. In recent years, there has been an increasing research interest in residential self-selection and a wide range of issues has been studied. These include the importance of travel-related attitudes in residential choice (e.g., Schwanen and Mokhtarian 2007; Chatman 2009), the interrelationships among built environment, attitude, and travel behavior (e.g., Kitamura et al. 1997; Bagley and Mokhtarian 2002), and the methodologies to address residential self-selection (e.g., Bhat and Eluru 2009; Cao 2010), among others.

Despite the number of studies on this topic, most of them have been conducted in North American cities, where residential choice is largely market driven and the housing system offers opportunities for individuals who can afford it to express their travel-related preference through their choice of built environment. In many societies and countries in the world, especially the developing world, residential choice is much constrained not only by what individuals can afford, but also by the limited choices that the housing system may provide. China is one such example for which the housing system used to be controlled by the heavy hand of the state and a large percentage of people did not have much freedom in residential choice. Moreover, the travel-related attitudes of individuals in societies like China may be quite different from those in North American cities because of the differences in levels of socioeconomic development, lifestyle, and social norms. Studying residential self-selection in other parts of the world may improve our understanding of this issue. This paper aims to make such a contribution by discuss-

1'dgwang@hkbu.edu.hk

Copyright 2014 Donggen Wang and Tao Lin.

Licensed under the Creative Commons Attribution - NonCommercial License 3.0. 
ing the specificities of the residential self-selection issue in urban China and suggesting how to cope with this issue when examining the relationship between built environment and travel behavior in the Chinese context. The rest of the paper is structured as follows: Section 2 provides a literature background and discusses the concepts, methodologies, and empirical evidence concerning residential self-selection; Section 3 analyzes residential self-selection in the Chinese context; and the last section summarizes the major arguments and makes conclusions.

\section{Residential self-selection: Concepts, methodologies, and evidences}

Studies on residential self-selection address the importance of travel-related attitudes and preferences in determining residential places (Bohte et al. 2009; Chatman 2009). Mokhtarian and Cao (2008) argues that residential self-selection is a choice not only induced by individuals' preferences and attitudes, but also constrained by abilities and needs defined by socio-demographic traits. The self-selection hypothesis is supported by findings on the importance of travel-related attitudes in determining residential choices (e.g., Lund 2006; Chatman 2009; Schwanen and Mokhtarian 2007). Lund (2006) reports that access to transit is one of the most important reasons driving individuals to choose to live near rail stations in California. Schwanen and Mokhtarian (2007) reports that attitudes toward travel and land use significantly affect residential choices even after socio-demographics, personality/lifestyle, and auto availability are controlled. Nevertheless, Chatman (2009) argues that the importance of travel-related attitudes in housing choice should not be overestimated because travel accessibility is only one of the many factors influencing housing choice, and the supply of preferred neighborhoods may be constrained in housing markets, thus lowering the probability of finding the preferred neighborhood.

Mokhtarian and Cao (2008) identifies seven modeling approaches that can be or have been adopted to address the residential self-selection issue in travel behavior studies, including direct questioning, statistical control, structural equations model, and longitudinal design. They suggest that the ideal method to address this issue is the longitudinal structural equations modeling approach, because it has most of the strengths of the other modeling approaches (Mokhtarian and Cao 2008). One additional approach to addressing the self-selection issue is by comparing the travel behavior (e.g., distance traveled) of individuals living in their preferred neighborhoods (consonant residents) to that of individuals not living in their preferred neighborhoods (dissonant residents) (Schwanen and Mokhtarian 2005). More recently, Cao et al. (2010) proposes to apply the so-called propensity score matching method to quantify the contribution of residential self-selection to the connection between built environment and travel behavior. Whichever modeling approach is adopted, incorporating the travel-related attitudes and preferences into the analysis appears to be the key in addressing the issue. Bohte et al. (2009) discusses the factors that need to be considered. They argue that perceptions of the travel-related built environment attributes are probably more important than the actual attributes in explaining travel behavior. Further, whether attitude influences behavior or behavior influences attitude has different implications for the role of travel-related attitudes. In addition, travel habits may influence the attitude-behavior relationship.

Existing studies have generated important findings on the effects of residential self-selection. Cao et al. (2009) provides an extensive review of the major empirical findings reported in the literature. Most studies suggest that residential self-selection is a statistically significant factor confounding the relationship between built environment and travel behavior. However, built environment variables remain significant even after the effects of residential self-selection are controlled (Mokhtarian and Cao 2008; Cao et al. 2009). Several studies quantify the relative contributions of residential self-selection and built environments to travel behavior mostly using the sample selection model (e.g., Zhou and Kockelman 2008; Cao 2009; Bhat and Eluru 2009) or propensity score matching (e.g., Cao 2010; Cao et al. 2010). 
They suggest that the contributions by the built environment range from 51 percent to 81 percent; built environment seems to contribute more than residential self-selection to explain travel behavior (Zhou and Kockelman 2008; Cao 2009; Bhat and Eluru 2009; Cao 2010; Cao et al. 2010).

Notwithstanding the established literature in this field, most of the studies reviewed above are conducted in North America. Residential self-selection may not be an issue or have different influences in other parts of the world. Studies in other contexts may thus be needed to enrich the existing knowledge on this issue.

\section{Residential self-selection in the Chinese context}

There have been an increasing number of studies examining the association between built environment and travel behavior in urban China. Wang and Chai (2009) compares the commuting behavior of employees living in dwellings provided by work units (or danweis in Chinese) and those living in houses bought or rented from the market and finds that danwei residents have shorter commutes and are more likely to use a nonmotorized transport mode than other residents. Zhao (2013) reports that workers' commuting behavior, such as transport mode choice, and travel time is significantly related to some aspects of the built environment in Beijing. A study of Shanghai by Pan et al. (2009) reports that residents of pedestrian/cyclist-friendly neighborhoods travel shorter distances than those of other types of neighborhoods. Wang et al. (2011) finds that residents of newly developed neighborhoods, mostly in suburbs of Beijing, have longer travel times, longer trips, use more private cars, and spend less time on out-of-home activities than those in the traditional neighborhoods near the city center and with mixed land use. To what extent can the observed association between built environment and activity and travel behavior reported in the previous studies be attributed to residential self-selection? To the knowledge of the authors, there is hardly any travel behavior study of urban China that explicitly addresses the issue of residential self-selection except Næss (2010), which examines the residential location and travel behavior in Hangzhou, China, and suggests that the observed geographical differences in travel behavior cannot be explained by residential self-selection.

In this section, we will discuss the specificities of residential self-selection in the Chinese context and suggest how this issue should be addressed in future studies. The discussions in the previous section suggest that the keys to the residential self-selection issue are residential choice, travel-related attitudes, and how travel-related attitudes impact residential choice. In the following discussions, we will examine the residential self-selection issue in the urban Chinese context along these three dimensions.

\subsection{Residential choice}

The key to residential self-selection is that residents have the freedom to choose their residential environment and that most can find their preferred residential location. In the following discussions, we shall argue that residential choices in urban China are largely defined by the housing system, in which only about half of the population may have a choice of where to live, while the other half may have little freedom of residential choice because their housing is either bought or rented from their work units.

For a prolonged period of time before the 1980s, the Chinese state had monopolized housing provisions (Wu 1996; Wang and Li 2004). For most urban Chinese, housing was a welfare entitlement, and its allocation was decided by work units or municipal housing bureaus based on criteria such as job rank, seniority, and marital status (Wu 1996; Wang and Murie 2000). Individuals had virtually no freedom to choose where to live. The housing reform implemented in 1988 has fundamentally changed the housing system and resulted in diversified housing sources for urban Chinese (Huang 2004; Wang et al. 2011). First, although the responsibility of work units to provide housing for their employees was 
officially renounced in 1998 (Wang and Li 2004), housing from/through work units remains an important housing source, particularly for employees of government departments or public institutions. This is realized by either selling the work-unit-owned houses to the sitting tenants or by buying the newly built houses on land occupied by or newly allocated to the work units (Wu et al. 2013). Second, private housing has emerged as a major source of housing. A housing market in which commodity housing can be traded or rented according to market principles has been established (Wu 1996; Wang and Li 2004; Deng et al. 2009). The private housing market grants urban Chinese freedom to choose their residence based on affordability and preferences (Huang 2004; Wang and Li 2006; Wu et al. 2013). Some of the commodity housing is the so-called "replacement housing," which is built by private real estate developers for displaced people as compensation or sold to them at a discounted price. Third, in parallel with the development of commodity housing, a new public housing system (the so-called "affordable housing" or "jing-ji-shi-yong-fang" in Chinese) has been set up. Developed either by city governments or by developers on land provided by the government or obtained at very cheap land price, this type of housing is sold at prices much lower than market prices, and only people in the low-income strata are eligible to buy. Finally, to the three major categories of housing can be added self-built houses, including old private houses (e.g., Hutong in Beijing or Lilong in Shanghai) mostly built before 1949 and located in the city center, and houses in what is known as "villages in city" (mostly observed in southern Chinese cities like Guangzhou and Shenzhen), formerly rural villages now part of the urban area as a result of urban expansion. The living environments of this type of housing are generally undesirable, and therefore, usually accommodate the urban poor, migrant workers, or the floating population through renting. To show the relative importance of the different housing sources in urban China, Table 1 presents the numbers and percentages of households living in houses from the four different sources discussed above in the year 2010 (data in 2000 are also provided for comparison). It shows that the private housing market has become a major housing source. However, work units also remain an important housing source.

Table 1: Number and percentage of households living in houses from different sources in urban China (2010 and 2000).

\begin{tabular}{|l|l|l|l|l|}
\hline Housing Sources & \multicolumn{1}{|c|}{$\mathbf{2 0 1 0}$} & \multicolumn{1}{|c|}{ Percentage } & \multicolumn{1}{|c|}{$\mathbf{2 0 0 0}$} & Percentage \\
\hline Work Units (danwei) & & & & \\
\hline Purchased & $2,147,896$ & $12.30 \%$ & $2,401,075$ & $29.44 \%$ \\
\hline Housing Market & & & & \\
\hline First-hand House Purchased & $3,231,278$ & $26.02 \%$ & 751,224 & $9.21 \%$ \\
\hline Second-hand House Purchased & 618,097 & $4.98 \%$ & - & - \\
\hline Rental & $2,869,199$ & $23.11 \%$ & 561,724 & $6.89 \%$ \\
\hline Public Housing & & & & \\
\hline Affordable House Purchased & 627,345 & $5.05 \%$ & 533,396 & $6.54 \%$ \\
\hline Rental & 329,846 & $2.66 \%$ & $1,331,890$ & $16.33 \%$ \\
\hline Self-built & & & & \\
\hline Old private or villages-in-city houses & $2,039,582$ & $16.43 \%$ & $2,184,290$ & $26.78 \%$ \\
\hline Others & 553,219 & $4.46 \%$ & 391,318 & $4.80 \%$ \\
\hline Total & $12,416,562$ & 100.00 & $8,154,917$ & 100.00 \\
\hline
\end{tabular}

Sources: 1) National Bureau of Statistics of China, The 2010 population census of the People's Republic of China, http://www.stats.gov.cn/tjsj/pcsj/rkpc/6rp/indexch.htm, accessed June 26, 2013. 2) National Bureau of Statistics of China, The 2000 population census of the People's Republic of China, http:/www.stats.gov.cn/tjsj/ndsj/renkoupucha/2000pucha/ html/10804a.htm, accessed on June 26, 2013.

Note: Data in the table are based on the long form of the 2010 population census, and only 10 percent of the population is required to fill in the long form. 
Different housing sources have different implications for residential choice. Understandably, markethousing residents have the most freedom in residential choice, partly because of the diversity and quantity of supply and partly due to market-based principles. On the other hand, residents living in housing from work units - which is largely assigned by work unit according to job rank, marital status, etc.and replacement housing have little freedom in residential choice; to some extent, public (or affordable) housing residents do not have much choice either, because such housing is somehow assigned by the government according to eligibility and household size. Self-built houses usually accommodate the local urban poor and migrant workers, who are in the lowest social strata of Chinese cities and cannot afford better housing from the normal housing market. Their residential choice is rather constrained by what they can afford. Mostly developed on cheap land, affordable housing is often located in remote suburban areas with limited facilities. Work-unit houses are usually located adjacent to work places or in the same compound of the work units (Wang and Chai 2009). For historical reasons, housing from work units have more mixed land uses than other types of housing (e.g., availability of kindergartens, schools, hospitals in vicinity). For more details on the built environment characteristics of different housing types, readers are referred to Wang et al. (2011).

The above discussions suggest that for studying residential self-selection, the built environment, and travel behavior in urban China, it is important to acknowledge residents' housing source to correctly evaluate to what extent residential environment is the choice of the residents. In the empirical studies, one may need to include a variable on housing source and examine the relationships between travel attitude, travel behavior, and built environment in the context of different housing sources.

\subsection{Travel-related attitudes and their influence on residential choice}

According to Bohte et al. (2009), travel-related attitudes are a psychological tendency expressed by evaluating a particular entity (e.g., cars or travel behavior) with some degree of favor or disfavor (Eagly and Chaiken 1993; Bohte et al. 2009). Attitudes can be very specific (e.g., attitude toward taking bus to school tomorrow) or very general (attitude toward driving a car for commuting). The entity can be different components of travel behavior, including travel modes, trip characteristics, and destination features (Bohte et al. 2009). It is commonly believed that travel-related attitudes are not only developed individually but also influenced by social norms and values, cultures, and lifestyles. In this connection, it is worthwhile to discuss the specificities of travel-related attitudes and preferences and their potential influence on residential choice in the Chinese context.

\section{Preference for short commute}

Before the introduction of economic and urban reforms in the 1980s, most urban Chinese workers were the employees of state or collective-owned institutions or enterprises and worked and lived in the same danwei compounds (Wang and Murie 2000; Gaubatz 1999; Wang and Chai 2009). An important feature of danwei compounds is the proximity between work and residence. This historical legacy has imprinted not only the built environment and spatial structure of major Chinese cities, but also individuals' attitude toward distance between work and residence as well as commuting. Though housing reform has delinked the connection between work and residence, for many urban Chinese who previously took short commuting for granted, in combination with the low car-ownership rate and imbalanced urban spatial structure, the distance between workplace and residential location is no doubt an important consideration, and proximity between the two would be much favored. Wu et al. (2013) and Wu (2009) provide empirical evidence to support this argument. With data from a survey of 3481 households in Beijing in 2009, Wu et al. (2013) found that households are more likely to choose to reside in those neighborhoods with high job accessibility and short commuting time. In a study of young 
housing consumers in Guangzhou, Wu (2009) reveals that proximity to workplace is the second most important determinant of housing choice, after access to a public transport network. Empirical evidence from western cities seems to suggest that accessibility issues such as distance to workplace are not necessarily an important factor influencing people's residential choice (Kim and Morrow-Jones 2005; Morrow-Jones and Kim 2009).

This preference for short commutes may have important implications for residential self-selection and travel behavior. For instance, individuals may self-select into neighborhoods near their workplaces and choose nonmotorized transport modes for commuting to realize their preference for shorting commutes, not their preference for using a nonmotorized transport mode for commuting. Further, the observed relationship between built environment and commuting behavior may be the result of influences from not only the built environment, but also the preference for short commutes. To examine the influence of this preference, one may explicitly ask respondents if "short commuting" is an important consideration in residential choice. Preference for short commutes has not been much considered in existing studies on residential self-selection. Given the importance of this travel-related attitude in the Chinese context, future travel behavior studies on residential self-selection may need to consider this preference.

Preference for good accessibility to public transport

Although car ownership and car use in China have experienced rapid growth in the last decade, public transport (e.g., bus, subway) remains the choice of transport mode for daily traveling for the majority of urban residents in China. According to the 2012 China Statistical Yearbook (NBSC 2012), even in the most developed cities like Beijing and Tianjin, the percentages of car ownership over total population are only $19.18 \%$ and $11.47 \%$, respectively. This is a major difference between Chinese cities and North American cities where private car is the dominant transport mode. Thus, good accessibility to public transport is an important consideration for many urban Chinese when making their residential choices. This is empirically supported by studies in Beijing (Wang and Li 2004) and Guangzhou (Wang and $\mathrm{Li}$ 2006), with the findings suggesting that residents in both cities prefer neighborhoods with good public transport connections to other city districts. While people in Europe or North America may prefer to choose neighborhoods with good public transport, and their preferences can be both economically constrained and attitude-induced self-selection, the preference for neighborhoods with good public transport connections in China is more likely to be economically constrained self-selection because the majority of people do not have access to private cars. This difference suggests that public-transportrelated residential self-selection in the Chinese context might be better accounted for by the sorting effects of socio-demographic characteristics rather than attitudes toward public transport (Mokhtarian and Cao 2008).

Preference for proximity to markets/shops for daily goods

Walking or biking to stores for daily shopping is an important part of individuals' walking/biking behavior. Studies in Austin, Texas, disclose how preference for stores within walking distance influences individuals' pedestrian shopping trips within neighborhoods and confounds the relationship between built environment and walking behavior (Cao et al. 2006). There are important differences in shopping behavior between Chinese and Westerners. Most Westerners do their major shopping for daily goods on a weekly basis. However, shopping daily for fresh vegetables, meat, etc., is very common for Chinese people because they believe that the freshness of food affects how it tastes and how healthy it is. As a result of this culture difference, it is understandable that proximity to food markets or shops for daily goods is a very important consideration for many Chinese people when making residential choices. Wang and $\operatorname{Li}(2004,2006)$ find empirical evidence from their studies in Beijing and Guangzhou, sug- 
gesting that proximity to markets for daily goods is a significant determinant of individuals' residential choice.

This preference for proximity to food markets has significant, yet distinct, implications for travel behavior studies in China. When studying the influence of built environment on grocery shopping activity or walking/biking behavior, such as the frequency of shopping activities and walking trips, one may need to consider whether and how this food culture-induced preference contributes to the influence. To determine the contribution of this preference, one possible approach is to compare the shopping behavior of the so-called consonant residents with that of the dissonant residents living in the same neighborhoods with good proximity to food markets. If no significant differences in shopping behavior between these two groups of residents are found, the preference for proximity to food markets may play only a marginal role. Alternatively, one may compare the shopping behavior of residents living in neighborhoods with significantly different levels of proximity to food markets. In this case, if no significant differences are found in shopping behavior between residents living in different neighborhoods, the preference for proximity to food markets is probably very important in explaining shopping behavior. In making the comparisons, one may need to note that a difference in shopping frequency may also be caused by the larger effort required to shop frequently if someone lives far away from relevant facilitiesi.e., the phenomenon of "distance decay" (Maddison et al. 1996).

\section{Environmental concern or status-seeking}

Environmental concern is an important attitude having an impact on travel behavior-specifically, driving behavior - in developed societies. People with a strong environmental concern are found to be more likely to reside in higher-density neighborhoods in downtown areas and have reduced auto use (Schwancen and Mokhtarian 2007). However, as a developing country with economic development a top priority for the last three decades, China is facing severe environmental problems. One of the reasons is that people in general do not have a strong sense of caring for the environment. For example, driving a car is considered a symbol of social status rather than a convenient and time-saving way of transport. It is not surprising to find that although driving a car probably takes longer than riding public transit because of traffic congestion, many still choose to travel by car. It is thus unlikely that people would drive less because they care about the environment. For this reason, we believe that environmental concern may not be an important factor influencing residential self-selection in the Chinese context.

\section{Conclusion}

In an attempt to contribute some viewpoints on residential self-selection from the perspective of societies other than those of North American cities, this paper has analyzed the issues related to residential selfselection in the Chinese context. One of the major arguments we have made is that the housing source has important implications for residential choice and thus, residential self-selection. Although more urban Chinese may increasingly buy or rent houses from the housing market, a significant percentage are still rather constrained in residential choice by either affordability or the structure of the housing system. We suggest that the study of residential self-selection in urban China needs to acknowledge the source of housing and examine to what extent individuals have freedom in residential choice. Failing to acknowledge this issue may lead to overestimation of the contribution of residential self-selection, and hence underestimation of the influence of built environment, on travel behavior. The rich spectrum in the degree of freedom concerning residential choice in urban China offers an ideal case to explore the causality involved in the relationship between built environment and travel behavior and the importance of residential self-selection in this relationship. This research finding may also be applicable to the 
Eastern European countries or societies that have experienced similar transitions from state-monopolized to market-driven housing systems.

In addition, we have identified several travel-related attitudes or preferences that may induce residential self-selection in the Chinese context: preference for short commutes, good accessibility to public transport, proximity to market for daily goods shopping, etc. We have argued that studying the relationship between built environment and travel behavior in urban China may need to account for the effect of residential self-selection by taking into consideration these travel-related attitudes.

\section{Acknowledgements}

This research was supported financially by a General Research Fund (GRF) grant from Hong Kong Research Council: HKBU244610. We are very grateful for the anonymous reviewers and the special issue editor for their invaluable and constructive comments, which helped improve the quality of the paper. Any remaining errors are, of course, our own responsibility. 


\section{References}

Bagley, M. N., and P. L. Mokhtarian. 2002. The impact of residential neighborhood type on travel behavior: a structural equations modeling approach. Annals of Regional Science 26: 279-197. doi:10.1007/s001680200083.

Bhat, C. R., and N. Eluru. 2009. A copula-based approach to accommodate residential self-selection effects in travel behavior modeling. Transportation Research Part B: Methodological 43: 749-765. doi:10.1016/j.trb.2009.02.001.

Bohte, W., K. Maat, and B. V. Wee. 2009. Measuring attitudes in research on residential self-selection and travel behavior: A review of theories and empirical research. Transport Reviews 29(3): 325-357. doi:10.1080/01441640902808441.

Cao, X., S. L. Handy, and P. L. Mokhtarian. 2006. The influence of the built environment and residential self-selection on pedestrian behavior: Evidence from Austin, TX. Transportation 33: 1-20. doi:10.1007/s11116-005-7027-2.

Cao, X. 2009. Disentangling the influence of neighborhood type and self-selection on driving behavior: An application of sample selection model. Transportation 36: 207-222. doi:10.1007/s11116-0099189-9.

Cao, X., P. L. Mokhtarian, and S. L Handy. 2009. Examining the impacts of residential self-selection on travel behavior: A focus on empirical findings. Transport Reviews 29(3): 359-395. doi:10.1080/01441640802539195.

Cao, X., 2010. Exploring causal effects of neighborhood type on walking behavior using stratification on the propensity score. Environment and Planning A 42: 487-504. doi:10.1068/a4269.

Cao, X., Z. Xu, and Y. Fan. 2010. Exploring the connections among residential location, self-selection, and driving: Propensity score matching with multiple treatments. Transportation Research Part A 44: 797-805. doi:10.1016/j.tra.2010.07.010.

Chatman, D. G. 2009. Residential choice, the built environment, and nonwork travel: Evidence using new data and methods. Environment and Planning A 41: 1072-1089. doi:10.1068/a4114.

Deng, L., Q. Shen, and L. Wang. 2009. Housing policy and finance in China: A literature review. U.S. Department of Housing and Urban Development. www.chinaplanning.org/Publications/Lan\%20 Deng\%20-\%20Housing\%20Policy\%20and\%20Finance\%20In\%20China.pdf. Accessed 13 July 2013.

Eagly, A. and S. Chaiken. 1993. The Psychology of Attitude. Fort Worth, Texas: Harcourt, Brace and Jovanovich.

Gaubatz, P. 1999. China’s urban transformation: Patterns and processes of morphological change in Beijing, Shanghai and Guangzhou. Urban Studies 36(9): 1451-1521. doi:10.1080/0042098992890.

Huang, Y. 2004. Housing markets, government behaviors, and housing choice: A case study of three cities in China. Environment and Planning A 36, 45-68. doi:10.1068/a35158.

Kim, M. J. and H. A. Morrow-Jones. 2005. Current determinants of residential location decisions. In Access to Destinations, eds. D. M. Levinson and K. J. Krizek, 149-170. London: Elsevier.

Kitamura, R., P. L. Mokhtarian, and L. Laidet. 1997. A micro-analysis of land use and travel in five neighborhoods in the San Francisco Bayarea. Transportation 24: 125-158. doi:10.1023/A:1017959825565.

Lund, H., 2006. Reasons for living in a transit-oriented development, and associated transit land use. Journal of the American Planning Association 72(3): 357-366. doi:10.1080/01944360608976757.

Maddison, D., D. W. Pearce, O. Johansson, and E. Calthrop. 1996. The True Costs of Road Transport. London: Earthscan Publications. 
Mokhtarian, P. L., and X. Cao. 2008. Examining the impacts of residential self-selection on travel behavior: A focus on methodologies. Transportation Research Part B 42(3): 204-228. doi:10.1016/j. trb.2007.07.006.

Morrow-Jones, H. A., and M. J. Kim. 2009. Determinants of residential location decisions among the pre-elderly in central Ohio. Journal of Transport and Land Use 2(1): 47-64.

Næss, P., 2010. Residential location, travel and energy use: The case of Hangzhou metropolitan area. Journal of Transport and Land Use 3(3): 27-59. doi:10.5198/jtlu.v3i3.98.

National Bureau of Statistics of China. 2012. China Statistical Yearbook. www.stats.gov.cn/tjsj/ndsj/2012/ indexch.htm. Accessed June 29, 2013.

Pan, H., Q. Shen, and M. Zhang. 2009. Influence of urban form on travel behavior in four neighborhoods of Shanghai. Urban Studies 46(2): 275-294. doi:10.1177/0042098008099355.

Schwanen, T., and P. L. Mokhtarian. 2005. What if you live in the wrong neighborhood? The impact of residential neighborhood type dissonance on distance traveled. Transportation Research Part D 10: 127-151. doi:10.1016/j.trd.2004.11.002.

Schwanen, T. and P. L. Mokhtarian. 2007. Attitudes toward travel and land use and choice of residential neighborhood type: Evidence from the San Francisco Bay Area. Housing Policy Debate 18(1): 171-207. doi:10.1080/10511482.2007.9521598.

Wang, D., and S. Li. 2004. Housing preferences in a transitional housing system: The case of Beijing, China. Environment and Planning A 36: 69-87. doi:10.1068/a35263.

Wang, D., and S. Li. 2006. Socio-economic differentials and stated housing preferences in Guangzhou, China. Habitat International 30: 305-326. doi:10.1016/j.habitatint.2004.02.009.

Wang, D., and Y. Chai. 2009. The jobs-housing relationship and commuting in Beijing, China: The legacy of Danwei. Journal of Transport Geography 17(1): 30-38. doi:10.1016/j.jtrangeo.2008.04.005.

Wang, D., Y. Chai, and F. Li. 2011. Built environment diversities and activity-travel behavior variations in Beijing, China. Journal of Transport Geography 19(6): 1173-1186. doi:10.1016/j.jtrangeo.2011.03.008.

Wang, Y. P., and A. Murie. 2000. Social and spatial implications of housing reform in China. International Journal of Urban and Regional Research 24(2): 397-417. doi:10.1111/1468-2427.00254.

Wu, F. 1996. Changes in the structure of public housing provision in urban China. Urban Studies 33: 1601-1627. doi:10.1080/0042098966529.

Wu, P. 2009. Housing environment preference of young consumers in Guangzhou, China: Using the analytic hierarchy process. Property Management 28(3): 174-192. doi:10.1108/02637471011051318.

Wu, W., W. Zhang, and G. Dong. 2013. Determinant of residential location choice in a transitional housing market: Evidence based on micro survey from Beijing. Habitat International 39: 16-24. doi:10.1016/j.habitatint.2012.10.008.

Zhao, P., 2013. The impact of the built environment on individual workers' commuting behavior in Beijing. International Journal of Sustainable Transportation 7(5): 389-415. doi:10.1080/15568318. 2012.692173.

Zhou, B. and K. Kockelman. 2008. Self-selection in home choice: Use of treatment effects in evaluating relationship between built environment and travel behavior. Transportation Research Record: Journal of the Transportation Research Board 2077: 54-61. doi:10.3141/2077-08. 